\title{
Novel synthetic analogues of avian $\beta$-defensin-12: the role of charge, hydrophobicity, and disulfide bridges in biological functions
}

\author{
Ming Yang ${ }^{1}$, Chunye Zhang ${ }^{1}$, Michael Z. Zhang ${ }^{2,3}$ and Shuping Zhang ${ }^{1,3^{*}}$
}

\begin{abstract}
Background: Avian $\beta$-defensins (AvBD) possess broad-spectrum antimicrobial, LPS neutralizing and chemotactic properties. AvBD-12 is a chemoattractant for avian immune cells and mammalian dendritic cells (JAWSII) - a unique feature that is relevant to the applications of AvBDs as chemotherapeutic agents in mammalian hosts. To identify the structural components essential to various biological functions, we have designed and evaluated seven AvBD analogues.

Results: In the first group of analogues, the three conserved disulfide bridges were eliminated by replacing cysteines with alanine and serine residues, peptide hydrophobicity and charge were increased by changing negatively charged amino acid residues to hydrophobic (AvBD-12A1) or positively charged residues (AvBD-12A2 and AvBD-12A3). All three analogues in this group showed improved antimicrobial activity, though AvBD-12A3, with a net positive charge of +9 , hydrophobicity of $40 \%$ and a predicted CCR2 binding domain, was the most potent antimicrobial peptide. AvBD-12A3 also retained more than $50 \%$ of wild type chemotactic activity. In the second group of analogues (AvBD-12A4 to AvBD12A6), one to three disulfide bridges were removed via substitution of cysteines with isosteric amino acids. Their antimicrobial activity was compromised and chemotactic activity abolished. The third type of analogue was a hybrid that had the backbone of AvBD-12 and positively charged amino acid residues AvBD-6. The antimicrobial and chemotactic activities of the hybrid resembled that of AvBD-6 and AvBD-12, respectively.

Conclusions: While the net positive charge and charge distribution have a dominating effect on the antimicrobial potency of $A \vee B D s$, the three conserved disulfide bridges are essential to the chemotactic property and the maximum antimicrobial activity. Analogue AvBD-12A3 with a high net positive charge, a moderate degree of hydrophobicity and a CCR2-binding domain can serve as a template for the design of novel antimicrobial peptides with chemotactic property and salt resistance.
\end{abstract}

Keywords: Avian $\beta$-defensin analogues, Antimicrobial activity, Chemotactic activity, Net positive charge, Hydrophobicity, Disulfide bridges

\footnotetext{
* Correspondence: zhangshup@missouri.edu

${ }^{1}$ Department of Veterinary Pathobiology, College of Veterinary Medicine, University of Missouri, Columbia, MO 65211, USA

${ }^{3}$ Veterinary Medical Diagnostic Laboratory, College of Veterinary Medicine, University of Missouri, Columbia, MO 65211, USA

Full list of author information is available at the end of the article
}

\section{Ciömed Central}

(c) The Author(s). 2017 Open Access This article is distributed under the terms of the Creative Commons Attribution 4.0 International License (http://creativecommons.org/licenses/by/4.0/), which permits unrestricted use, distribution, and reproduction in any medium, provided you give appropriate credit to the original author(s) and the source, provide a link to the Creative Commons license, and indicate if changes were made. The Creative Commons Public Domain Dedication waiver (http://creativecommons.org/publicdomain/zero/1.0/) applies to the data made available in this article, unless otherwise stated. 


\section{Background}

Rapid emergence of antimicrobial resistance poses a major global threat to public health and the economy $[1,2]$. Excessive use and misuse of antibiotics in medicine and food production contribute to the rise of drug resistant pathogens [3, 4]. Control and prevention of antibiotic resistance call for holistic strategies including judicious use of antimicrobials, effective diagnostic tools, and novel therapeutic agents that are less likely to trigger resistance [5].

Beta-defensins are small, cationic, antimicrobial peptides found in different living organisms [6-9]. These endogenous peptides constitute the first line of innate defense against pathogenic bacteria, fungi, and viruses $[10,11]$. Beta-defensins possess various biological properties, including broad-spectrum microbicidal activity, neutralization of LPS, activation of macrophages and dendritic cells, chemoattraction of dendritic cells, monocytes, and T-lymphocytes to the site of infection $[7,10,12]$. The microbicidal activity of defensins is achieved mainly through initial electrostatic attraction between positively charged amino acid residues of the peptides and negatively charged microbial surface components and subsequent microbial membrane damage which is followed by interacting with intracellular targets [13-15]. The chemotactic function of $\beta$ defensins is mediated by $\mathrm{CC}$-chemokine receptors, such as CCR2 and CCR6 [16-18]. These natural antimicrobial peptides with complex mechanisms of action represent potentially a novel class of antimicrobials [13, 19]. However, several challenges must be addressed in order to develop $\beta$-defensins for therapeutic use which include retaining the biological activities under physiological conditions and the ease of production and purification of recombinant or synthetic peptides $[20,21]$.

Most defensin peptides characterized to date have a net positive charge, ranging from +2 to +9 , and hydrophobicity of approximately $30-50 \%$ [15]. It has been reported that the three conserved disulfide bridges are required for the chemotactic function, but not the antimicrobial activity [17, 22-25]. Data from our laboratory showed that reduced (or linear form) AvBDs are fully active against bacterial pathogens whereas AvBDs without correctly folded disulfide bridges are not $[21,26]$. To further understand the structural and functional characteristics of AvBDs, seven analogues were designed by replacing the negatively charged residues (D and $E$ ) and/or cysteines $(C)$ with either positively charged residues $(\mathrm{H}, \mathrm{K}$, and $\mathrm{R})$, hydrophobic residues (A, I, L, and $\mathrm{V}$ ) or isosteric amino acids (Abu). The antimicrobial and chemotactic activities and salt-resistance of the analogues as well as their wild type parent peptides have been evaluated.

\section{Methods}

\section{Design and synthesis of peptides}

The three dimensional structures of AvBDs were predicted by using the I-TASSER program (http://zhan glab.ccmb.med.umich.edu/I-TASSER). The distribution of positively charged amino acids were evaluated using PyMOL (https://www.pymol.org/). Group 1 analogues, including AvBD-12A1, A2 and A3 were linear peptides, in which the six cysteines $\left(\mathrm{C}^{1} \mathrm{C}^{2} \mathrm{C}^{3} \mathrm{C}^{4} \mathrm{C}^{5} \mathrm{C}^{6}\right.$ or C5C12C17C27C34C35) were replaced with structurally similar amino acid residues (alanine and serine) as follows: AvBD-12A1: A5A12A17A27A34A35, AvBD12A2: S5S12S17A27A34A35, and AvBD-12A3: A5A12A 17S27S34S35. Additional modifications were introduced to these analogues to alter peptide hydrophobicity and charge. In AvBD-12A1, the four negatively charged amino acid residues (D3D8E21E29) were replaced with one polar and three hydrophobic amino acid residues (H3V8L21I29). In AvBD-12A2 and AvBD-12A3, D3D8E21E29 were substituted with positively charged residues R3K8K21R29. Group 2 analogues, including AvBD-12A4, AvBD-12A5 and AvBD-12A6 had reduced number of disulfide bridges without any additional modifications. To remove disulfide bridges, the cysteine residues $\left(\mathrm{C}^{1} \mathrm{C}^{2} \mathrm{C}^{3} \mathrm{C}^{4} \mathrm{C}^{5} \mathrm{C}^{6}\right.$ or $\mathrm{C} 5 \mathrm{C} 12 \mathrm{C} 17 \mathrm{C} 2$ 7C34C35) of AvBD-12 were replaced with isosteric $\alpha$ aminobutyric acids (Abu, U) to create AvBD-12A4 (U5C12C17C27U34C35), A5 (U5U12C17U27U34C35), and A6 (U5U12U17U27U34U35). Group 3 included a single hybrid peptide, namely AvBD-12/6. This analogue was designed using the backbone of AvBD-12, in which the negatively charged amino acid residues (D3D8E21E29) of AvBD-12 were replaced with amino acids (H3Q8Y21S29) of AvBD-6 at the corresponding positions. The hydrophobicity and charge of AvBD analogues at neutral $\mathrm{pH}$ were calculated using Peptide 2.0 (http://peptide2.com) and Peptide property calculator (PepCalc.com), respectively.

All peptides were custom synthesized using the standard solid phase 9-fluorenylmethoxycarbonyl (Fmoc) method and purified by reverse phase high performance liquid chromatography (RP-HPLC) (Lifetein, Hillsborough, NJ). The analogues AvBD-12A4, -A5, AvBD-12/6, AvBD-6 and AvBD-12 with varying numbers of cysteine residues were subjected to oxidative folding as described previously [17]. Electrospray ionization mass spectrometry (ESI-MS) was performed to confirm the correct formation of disulfide bridges between $\mathrm{Cys}^{1}-\mathrm{Cys}^{5}, \mathrm{Cys}^{2}-\mathrm{Cys}^{4}$ and $\mathrm{Cys}^{3}-\mathrm{Cys}{ }^{6}$. The purity of the synthetic AvBD analogues was over 98.5\% as verified by liquid chromatography-mass spectrometry (LC-MS) (Lifetein, Hillsborough, NJ).

\section{Antimicrobial activity of AvBD analogues}

Escherichia coli (ATCC 25922), Pseudomonas aeruginosa (ATCC 27853), Salmonella enteric serovar Typhimurium 
(ATCC 14028) and Staphylococcus aureus (ATCC 29213) were used to assess the antimicrobial activity of AvBD analogues. All bacterial strains were grown on Luria-Bertani (LB) agar plates or Trypticase Soy Agar with 5\% Sheep Blood (TSA, Thermo Fisher Scientific) plates at $37{ }^{\circ} \mathrm{C}$. Antimicrobial activity was determined by a colony counting assay $[21,26]$. In brief, bacteria were resuspended in 100-fold diluted Mueller Hinton II broth with $5 \mathrm{mM} \mathrm{NaCl}$ (minimal growth medium) to obtain a final bacterial concentration of $2 \times 10^{5} \mathrm{CFU} / \mathrm{ml}$. Twentyfive microliters of bacterial suspension and $25 \mu \mathrm{l}$ of AvBD analogue solution were mixed in the wells of a 96-well polypropylene microtiter plate ( $\mathrm{Nunc}^{\mathrm{Tn}}$, Thermo Fisher Scientific). The final peptide concentrations were $2,4,8,16,32,64$ and $128 \mu \mathrm{g} / \mathrm{ml}$. The minimal growth medium without AvBD peptide was included as a negative control. The bacterial-peptide mixtures were incubated at $37{ }^{\circ} \mathrm{C}$ for $2 \mathrm{~h}$, ten-fold serially diluted and plated on LB agar plates. The numbers of bacteria colonies were enumerated after $16 \mathrm{~h}$ of incubation at $37^{\circ} \mathrm{C}$. Antimicrobial activity was expressed as percent of killing using the following formula: $\left(\mathrm{CFU}_{\text {control }}-\mathrm{CFU}_{\text {treated }}\right) /$ $\mathrm{CFU}_{\text {control }} \times 100 \%$. To assess the resistance of AvBD analogues to sodium chloride $(\mathrm{NaCl})$, antimicrobial assays were carried out in the presence of $5 \mathrm{mM}, 50 \mathrm{mM}$, $100 \mathrm{mM}$ or $150 \mathrm{mM} \mathrm{NaCl}$. All assays were performed in triplicate.

\section{Minimum inhibitory concentrations of AvBD analogues}

The minimum inhibitory concentrations (MIC) of AvBDs were determined according to the guidelines of the Clinical and Laboratory Standards Institute (CLSI) [27, 28]. The Muller Hinton II broth used in standard MIC assays contained $20-25 \mathrm{mg} / \mathrm{L}$ of calcium and $10-12.5 \mathrm{mg} / \mathrm{L}$ of magnesium. Modified MICs of AvBDs were also determined under a low-salt and low-nutrient condition by using $100 \times$ diluted Muller Hinton II broth containing $0.2 \mathrm{mg} / \mathrm{L}$ of calcium, $0.1 \mathrm{mg} / \mathrm{L}$ magnesium and $5 \mathrm{mM}(292 \mathrm{mg} / \mathrm{L}) \mathrm{NaCl}$. MIC obtained under the low-salt and low-nutrient condition was referred to as MIC-ls. AvBD peptides were twofold serially diluted ( 2 to $256 \mu \mathrm{g} / \mathrm{ml}$ ) in a 96-well microtiter plate. An equal volume ( $\mu \mathrm{l})$ of bacterial suspension was added to each well of the plate. The final bacterial concentration in the wells was $5 \times 10^{5} \mathrm{CFU} / \mathrm{ml}$. The plate was incubated at $37^{\circ} \mathrm{C}$ for $24 \mathrm{~h}$ and the lowest concentration that completely prevented visible bacteria growth was recorded. To complement MIC-ls assays, the minimum bactericidal concentrations $(\mathrm{MBC})$ were evaluated by sub-culturing the contents of the first two clear wells obtained in the MIC-ls assay onto LB agar plates. All assays were conducted in triplicate. The lowest peptide concentration inhibiting more than $99 \%$ of bacterial growth was defined as MBC-ls. AvBD analogues were regarded as bactericidal if the $\mathrm{MBC}$ was no more than four times the MIC [29].

\section{Cell cytotoxicity assay}

Chicken macrophage cell lines MQ-NCSU and HD11 were maintained in RPMI-1640 media supplemented with $10 \%$ fetal bovine serum (FBS), $2 \%$ chicken serum, $100 \mathrm{U} / \mathrm{ml}$ penicillin and $100 \mu \mathrm{g} / \mathrm{ml}$ streptomycin (SigmaAldrich) at $37{ }^{\circ} \mathrm{C}$ in humidified air with $5 \% \mathrm{CO}_{2}$. CHO$\mathrm{K} 1$ cells were cultured in the same media without $2 \%$ chicken serum. For CCR2-transfected CHO-K1 cells, the medium was supplemented with $500 \mu \mathrm{g} / \mathrm{ml} \mathrm{G418}$ was added (Sigma-Aldrich) [26]. Murine immature dendritic cell line JAWSII (ATCC CRL-11904 $4^{\mathrm{mm}}$ ) was cultured in Alpha minimum essential medium containing $4 \mathrm{mM} \mathrm{L}$ glutamine, $1 \mathrm{mM}$ sodium pyruvate, $5 \mathrm{ng} / \mathrm{ml}$ murine Granulocyte macrophage colony-stimulating factor (GM-CSF), 20\% FBS, $100 \mathrm{U} / \mathrm{ml}$ penicillin and $100 \mu \mathrm{g} / \mathrm{ml}$ streptomycin at $37{ }^{\circ} \mathrm{C}$ in humidified air with $5 \% \mathrm{CO}_{2}$. The cell cytotoxicity was determined using the MTT (3-(4, 5-dimethylthiazol-2-yl)-2, 5-diphenyltetrazolium bromide metabolic activity assay according to the manufacturer's instruction (Thermo Fisher Scientific). Briefly, cells $\left(5 \times 10^{3}\right.$ cells/well $)$ were seeded in 96-well tissue culture plates, incubated overnight and treated with AvBDs at concentrations of 4, 16, 64 and $256 \mu \mathrm{g} / \mathrm{ml}$ for 4, 12, 24 and $48 \mathrm{~h}$ at $37{ }^{\circ} \mathrm{C}$. After treatment, $20 \mu \mathrm{l}$ of $12 \mathrm{mM}$ MTT solution was added to each well. The plate was incubated for $4 \mathrm{~h}$ and read at $540 \mathrm{~nm}$. Viability was expressed as percentage of viable cells relative to the untreated control. The experiments were performed in triplicate.

\section{Chemotaxis assay}

Migration of JAWSII and CCR2-CHO-K1 cells in response to AvBD-12 analogues was determined using a 48well microchemotaxis chamber technique as previously described [30]. Chemotaxis buffer (Minimum Essential Medium containing $0.1 \% \mathrm{BSA}, 100 \mathrm{U} / \mathrm{ml}$ penicillin, and $100 \mu \mathrm{g} / \mathrm{ml}$ streptomycin) and bacterial peptide $\mathrm{N}$ Formyl-methionyl-leucyl-phenylalanine (fMLF, SigmaAldrich) were included as negative and positive controls, respectively. The results were presented as chemotactic index (C.I.). C.I. = number of migrated cells induced by AvBDs / number of migrated cells induced by chemotactic buffer. The assay was repeated five times.

\section{Scanning electron microscopy (SEM)}

SEM was performed according to the procedure described by Cobo et al. [31]. S. Typhimurium was cultured in Mueller-Hinton (MH) broth to mid-log phase and harvested by centrifugation at $5000 \mathrm{~g}$ for $10 \mathrm{~min}$. Cell pellets were washed twice with $10 \mathrm{mM}$ PBS and resuspended at a final number of $10^{8} \mathrm{CFU}$. The cell suspension was incubated with $1 \times$ MIC-ls of AvBD-12A3, AvBD-12/6, wild-type AvBD-6 and AvBD- 12 at $37{ }^{\circ} \mathrm{C}$ for $30 \mathrm{~min}$. Bacterial pellets were fixed in $500 \mathrm{ml}$ of $2.5 \%(\mathrm{v} / \mathrm{v})$ 
glutaraldehyde in $0.2 \mathrm{M}$ cacodylate buffer at $4{ }^{\circ} \mathrm{C}$ overnight, washed twice with $0.2 \mathrm{M}$ cacodylate buffer and dehydrated through ethanol gradient $(30 \%, 50 \%, 70 \%$, $90 \%, 100 \%$ and again 100\%) for $15 \mathrm{~min}$ in each gradient. The samples were transferred into a mixture $(1: 1, \mathrm{v} / \mathrm{v})$ of ethanol and tertiary butanol and then pure tertiary butanol for 20 min each. After gold coating, the specimens were observed using a scanning electron microscope (Hitachi S-4700, Japan).

\section{Statistical analysis}

Data were presented as the means \pm standard deviation (SD). Differences between groups were analyzed using the one-way analysis of variance (ANOVA) followed by Duncan's test for multiple comparisons using software SPSS version 19.0 (IBM Corp., Armonk, NY). Differences at $p<0.05$ level were considered statistically significant, and at $p<0.01$ level were considered extremely significant.

\section{Results}

\section{Structural characteristics of AvBD-6 and AvBD-12 and their analogues}

Substitutions of $C^{1} C^{2} C^{3} C^{4} C^{5} C^{6}$ (or C5C12C17C27C34C35) by A5A12A17A27A34A35 (AvBD-12A1) not only eliminated the three disulfide bridges, but also elevated the hydrophobicity from 33\% (AvBD-12) to 47\%. Additional H3V8L21I29 for D3D8E21E29 substitutions further increased the hydrophobicity to $53 \%$ and the net positive charge from +1 (AvBD-12) to +5 (AvBD-12A1). Changes from $C^{1} C^{2} C^{3} C^{4} C^{5} C^{6}$ to S5S12S17A27A34A35 (AvBD12A2) or to A5A12A17S27S34S35 (AvBD-12A3) and changes from D3D8E21E29 to R3K8K21R29 (AvBD-12A2 and A3) eliminated all three disulfide bridges and increased the peptide hydrophobicity from $33 \%$ to $40 \%$ and the net positive charge from +1 to +9 . AvBD-12A4, A5, and A6 respectively lost disulfide bridge(s) $\mathrm{C}^{1-5} ; \mathrm{C}^{1-5}$ and $\mathrm{C}^{2-4} ; \mathrm{C}^{1-5}$, $\mathrm{C}^{2-4}$, and $\mathrm{C}^{3-6}$. $\mathrm{C}$ to $\mathrm{U}$ changes did not affect the peptide hydrophobicity and charge. The hybrid AvBD-12/6 with the backbone of AvBD-12 and the positively charged amino acids (H3Q8Y21S29) of AvBD-6 retained parent peptides' hydrophobicity (33\%) and an intermediate charge $(+5)$, compared to AvBD-6 (+7) and AvBD-12 (+1). The sequence, charge, hydrophobicity and number of disulfide bridges of analogues and wild-type AvBD-12 and AvBD-6 were listed in Table 1.

Superimposition of the predicted three dimensional structures of AvBD-12 and the structure of human $\beta$-defensin 6 (hBD6) revealed a similar N-terminal $\alpha$ helix and an adjacent $\beta 2-\beta 3$ loop, in addition to the conserved internal $\beta$-sheet domains (Fig. 1a). The $\alpha$-helix and $\beta 2-\beta 3$ loop have been identified by NMR spectroscopy as a contiguous binding surface for human CCR2 [32]. A comparison of the predicted three dimensional structures of AvBD-6 and AvBD-12 showed only the $\beta 2-\beta 3$ loop in AvBD-6. AvBD-6 had an N-terminal coil turn instead of an $\alpha$-helix. Peptide charge distribution analysis indicated that positively charged amino acid residues (H4R7R10R38R40) in the $\mathrm{N}$ - and C-termini of AvBD-6 formed a cluster whereas positively charged residues (H7R9K36) of AvBD-12 were separated by negatively charged residues (Fig. 1d). The N-terminal $\alpha$-helix and the $\beta 2-\beta 3$ loop were also seen in the predicted structures of AvBD-12A2 and AvBD-12A3. However, differences in the $\beta 2-\beta 3$ loop between AvBD-12A2 and A3 were identified (Fig. 2a). In AvBD-12A2, the $-\mathrm{C}=\mathrm{O}$ group in the main chain of F28 formed a hydrogen bond with the $-\mathrm{NH}$ group in the side chain of R29, resulting in the fold-back of R29 sidechain (Fig. 2b). In AvBD12A3, there was no hydrogen bond formation between $\mathrm{R} 29$ and F28. Instead, there are $\mathrm{C}-\mathrm{H} / \mathrm{O}$ interactions between the $-\mathrm{CH}$ groups in the aromatic $\pi$ ring of F28 and the $-\mathrm{C}=\mathrm{O}$ group of $\mathrm{F} 28$ as well as the $-\mathrm{CH}$ group in the side chain of S27, similar to what was reported previously [33]. Consequently, the side chain of R29 protruded towards the surface of the peptide and the aromatic ring of F28 in AvBD-12A3 turned in parallel with R29 side chain (Fig. 2c).

\section{Antimicrobial activity}

Group 1 analogues with increased net positive charge and hydrophobicity were significantly more effective $(\mathrm{p}<0.05)$ than the parent peptide AvBD-12 in killing E. coli, S. Typhimurium, $P$. aeruginosa, and $S$. aureus (Fig. 3). At $16 \mu \mathrm{g} / \mathrm{ml}$, AvBD-12, AvBD-12A1, AvBD$12 \mathrm{~A} 2$ and AvBD-12A3 killed 74.4\%, 88.6\%, 100\%, $100 \%$ of E. coli; $47.3 \%, 95.6 \%, 93.9 \%$, and $93.9 \% S$. Typhimurium; $35.5 \%, 72.3 \%, 98 \%$, and $100 \%$ of $P$. aeruginosa; and $52.9 \%, 77.2 \%, 83.1 \%$, and $91.7 \%$ of $S$. aureus, respectively. AvBD-12A2 and A3 with a net positive charge of +9 and hydrophobicity of $40 \%$ were more effective than AvBD-12A1 (charge $=+5$, hydrophobicity $=53 \%$ ). AvBD-12A2 and AvBD-12A3 which had identical charge and hydrophobicity but altered locations of alanine/serine residues exhibited different killing activities against $E$. coli or $P$. aeruginosa (Fig. 3). The bactericidal potency of group-1 analogues can be ranked as AvBD-12A3 > AvBD-12A2 > AvBD-12A1 > AvBD-12. Of the bacterial species tested, $E$. coli and $P$. aeruginosa were more susceptible than $S$. Typhimurium and $S$. aureus to AvBD-12A3 at medium concentrations, ranging from $8 \mu \mathrm{g} / \mathrm{ml}$ to $32 \mu \mathrm{g} / \mathrm{ml}$ (Fig. 3).

Group 2 analogues, including AvBD12A4, AvBD12A5, and AvBD-12A6 showed similar killing activity to that of AvBD-12 (Fig. 4). One exception was AvBD12A4 was an exception that lost one disulfide bridge $\left(C^{1}-C^{5}\right.$ or $\left.C 5-C 34\right)$ was shown to have weaker action than AvBD-12 against $S$. Typhimurium $(p<0.05)$. Group 3 or the hybrid analogue, AvBD-12/6 with the backbone 
Table 1 Amino acid sequences of avian $\beta$-defensin-12 (AvBD-12) analogues

\begin{tabular}{|c|c|c|c|c|}
\hline Defensin & Amino acid sequence ${ }^{a, b, c}$ & Charge & \# of S-S bonds & Hydrophobicity \\
\hline AvBD-12 & GPDSC $^{1}$ NHDRGLC ${ }^{2}$ RVGNC $^{3}$ NPGEYLAKYC ${ }^{4}$ FEPVILC $^{5} C^{6}{ }^{6}$ RLSPTPTKT & +1 & 3 & $33 \%$ \\
\hline AvBD-12-A1 & GPHSA NHVRGLA RVGNA NPGLYLAKYA FIPVILA A KPLSPTPTKT & +5 & 0 & $53 \%$ \\
\hline AvBD-12-A2 & GPRSS NHKRGLS RVGNS NPGKYLAKYA FRPVILA A KPLSPTPTKT & +9 & 0 & $40 \%$ \\
\hline AvBD-12-A3 & GPRSA NHKRGLA RVGNA NPGKYLAKYS FRPVILS S KPLSPTPTKT & +9 & 0 & $40 \%$ \\
\hline AvBD-12-A4 & GPDSU NHDRGLC ${ }^{2}$ RVGNC ${ }^{3}$ NPGEYLAKYC $C^{4}$ FEPVILU $C^{6}$ KPLSPTPTKT & +1 & 2 & $33 \%$ \\
\hline AvBD-12-A5 & GPDSU NHDRGLU ${ }^{2}$ RVGNC ${ }^{3}$ NPGEYLAKYU FEPVILU $C^{6}$ KPLSPTPTKT & +1 & 1 & $33 \%$ \\
\hline AvBD-12-A6 & GPDSU NHDRGLU RVGNU NPGEYLAKYU FEPVILU U KPLSPTPTKT & +1 & 0 & $33 \%$ \\
\hline AvBD-12/6 & GPHSC ${ }^{1}$ NHQRGLC ${ }^{2}$ RVGNC $^{3}$ NPGYYLAKYC $C^{4}$ FSPVILC $C^{5} C^{6}$ KPLSPTPTKT $^{2}$ & +5 & 3 & $33 \%$ \\
\hline AvBD-6 & SPIHAC ${ }^{1}$ RYQRGVC ${ }^{2}$ IPGPC ${ }^{3}$ RWPYYRVGSC $C^{4}$ GSGLKSC $C^{5} C^{6}$ VRNRWA & +7 & 3 & $33 \%$ \\
\hline
\end{tabular}

aisulfide bridges (S-S) between $\mathrm{C}^{1-5}, \mathrm{C}^{2-4}, \mathrm{C}^{3-6}$

${ }^{b} \mathrm{U}$ : a-aminobutyric acid

${ }^{c}$ Acidic amino acids, basic amino acids, and cysteines are highlighted in blue, red, and green color, respectively. $C^{1} C^{2} C^{3} C^{4} C^{5} C^{6}$ or $C 5 C 12 C 17 C 27 C 34 C 35$

of AvBD-12 and positively charged amino acid residues of AvBD-6 exhibited similar killing activities to that of AvBD-6 (Fig. 5).

\section{Minimum inhibitory concentration}

The MIC-ls of AvBD-12A1, AvBD-12A2 and AvBD-12A3 against $E$. coli, $S$. Typhimurium, and $P$. aeruginosa were 2 to 16-fold below that of AvBD-12, confirming the improved antimicrobial property of these analogues. The MIC-ls of these analogues against $P$. aeruginosa were 2 to 8-fold below that of AvBD-6. The ratio of MBC-ls/MIC-ls was equal to or below 4:1 for AvBD-12A2 and AvBD$12 \mathrm{~A} 3$ against the three Gram negative bacterial species tested, suggesting a bactericidal action [29]. The MIC-ls of AvBD-12A4, AvBD-12A5, and AvBD-12A6 with 2, 1 and 0 disulfide bridges, respectively, were higher than that of AvBD-12 and AvBD-6, indicating that removal of disulfide bridges compromised AvBD's antimicrobial function.

The MIC-ls of AvBD analogues was negatively correlated with the net positive charge. The correlation co-efficiencies (r) for E. coli, $S$. Typhimurium, P. aeruginosa, and S. aureus were $-0.7388, p<0.05 ;-0.8545, p<0.01 ;-0.8545, p<0.01$; and $-0.8727, p<0.01$, respectively. Although increasing hydrophobicity also resulted in improved antimicrobial potency, a positive correlation between hydrophobicity and antimicrobial activity was not found.
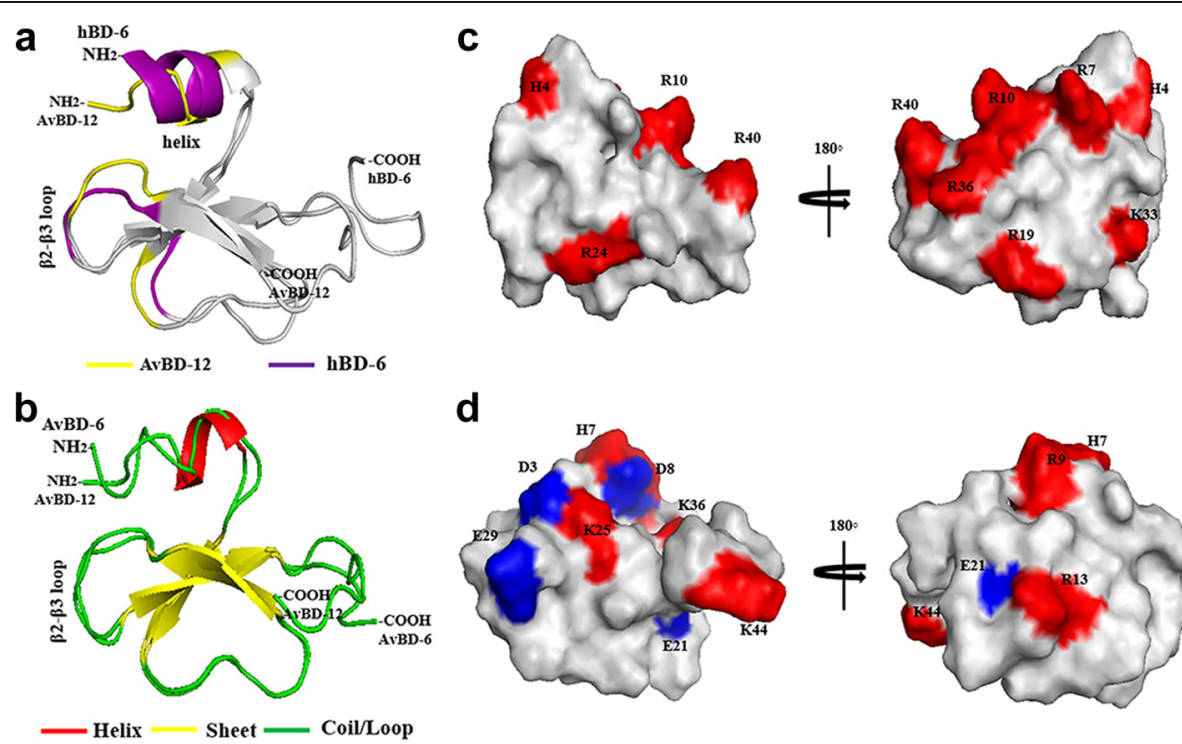

d
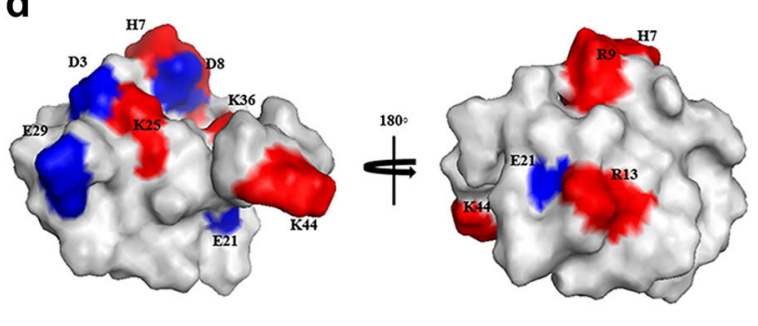

Fig. 1 The predicted three dimensional structures of AvBD-6 and AvBD-12. I-TASSER online service program was used to predict peptide structures. a Superimposition of the three dimensional structures of AvBD-12 and hBD-6. The CCR2 binding surface of hBD6 is highlighted in purple and the corresponding region in AvBD-12 is highlighted in yellow. b Superimposition of AvBD-12 and AvBD-6. c Distribution of positively and negatively charged amino acid residues in AvBD-12. d Distribution of positively charged amino acids in AvBD-6. Basic and acidic amino acids are highlighted in red and blue, respectively 


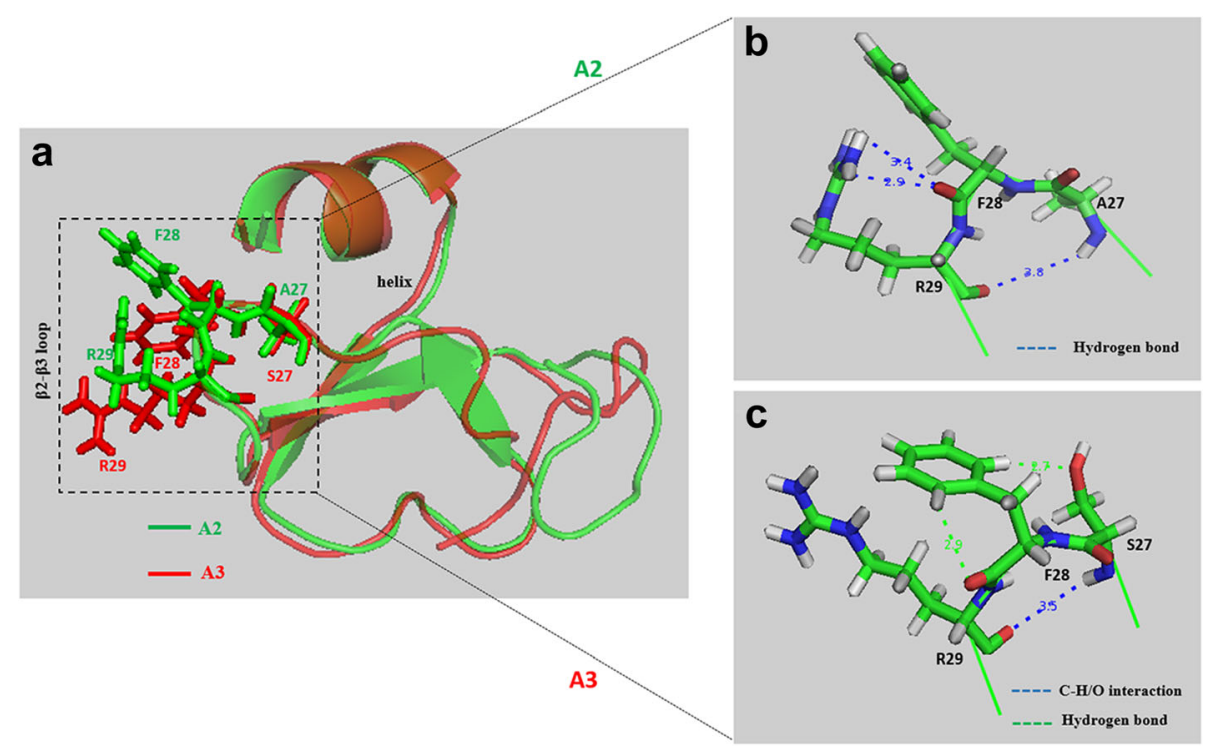

Fig. 2 The predicted $\beta 2-\beta 3$ loop in AvBD-12A2 and AvBD-12A3. a Superimposition of AvBD-12A2 (green) and AvBD-12A3 (red) revealing the structural differences in the $\beta 2-\beta 3$ loop, a component of CCR2 binding domain. $\mathbf{b}$ Enlarged review of the $\beta 2-\beta 3$ loop in AvBD-12A2. The hydrogen bond between the $-\mathrm{C}=\mathrm{O}$ group of $\mathrm{F} 28$ main chain and the $-\mathrm{NH}$ group of R29 side chain causes the arginine residue to fold back. $\mathbf{c}$ Enlarged review of the $\beta 2-\beta 3$ loop in AvBD-12A3. The $\mathrm{CHO}$ interactions between $\mathrm{S} 27-\mathrm{OH}$ groups and the - $\mathrm{CH}$ groups on the aromatic ring of F28 result in an outward protrusion of R29 and a parallel twist of F28 aromatic ring. Distance: $\AA$
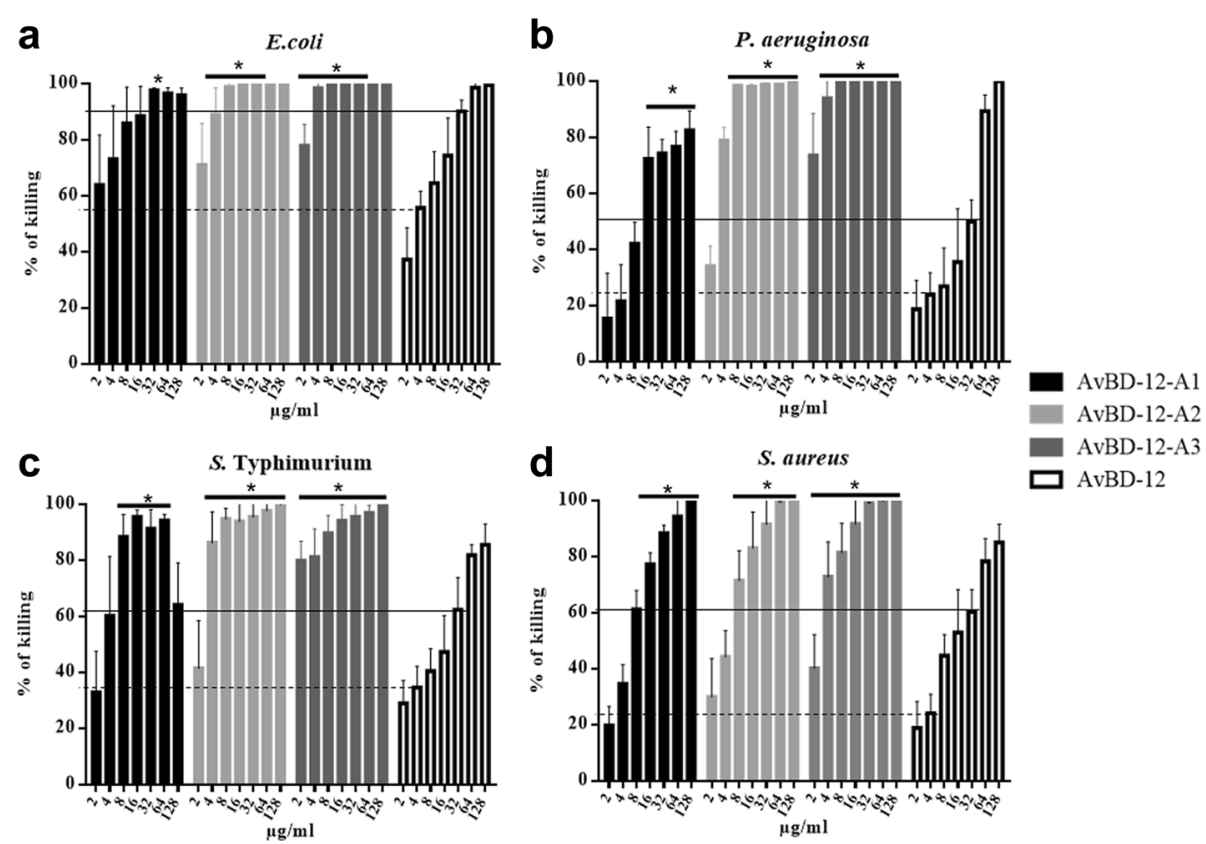

Fig. 3 Antimicrobial activity of group 1 analogues. Bacteria $\left(10^{5} \mathrm{CFU} / \mathrm{ml}\right)$ were incubated with peptides at various concentrations, ranging from 2 to $128 \mathrm{\mu g} / \mathrm{ml}$ at $37^{\circ} \mathrm{C}$ for $2 \mathrm{~h}$. Antimicrobial activity was presented as percent of killing compared to non-AvBD treated control. Antimicrobial activity of analogues against E. coli (a), P. aeruginosa (b), S. Typhimurium (c) and S. aureus (d). Data are means \pm SD $(n=3)$. Statistical analysis was performed using one-way analysis of variance (ANOVA) followed by Duncan's test for multiple comparisons using software SPSS version 19.0 (IBM Corp., Armonk, NY). Asterisk indicates statistically significant difference between the analogues and AvBD-12 at the same concentrations $\left({ }^{*} p<0.05\right)$. Solid line: average killing percent of $32 \mu \mathrm{g} / \mathrm{ml}$ of wild-type AvBD-12. Dash line: average killing percent of $4 \mu \mathrm{g} / \mathrm{ml}$ of wild-type AvBD-12 

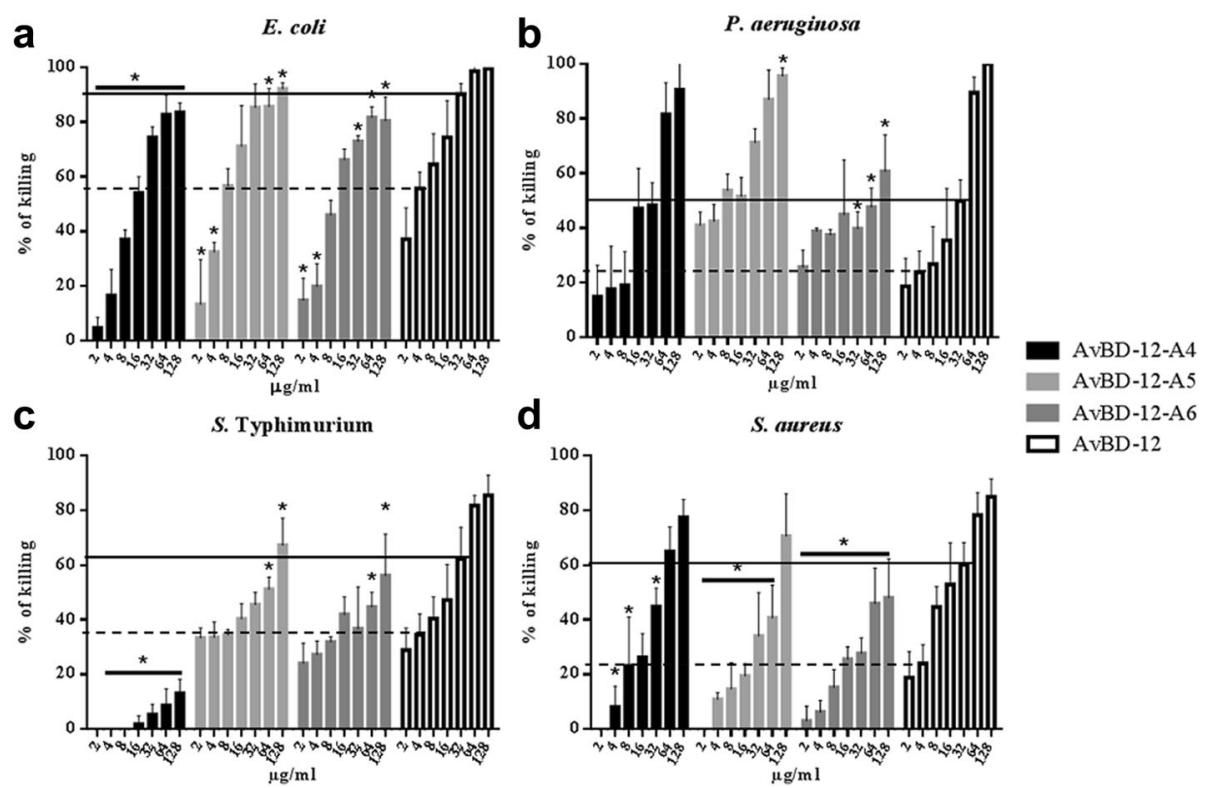

Fig. 4 Antimicrobial activity of group 2 analogues. Bacteria ( $\left.10^{5} \mathrm{CFU} / \mathrm{ml}\right)$ were incubated with peptides at various concentrations, ranging from 2 to $128 \mathrm{\mu g} / \mathrm{ml}$, at $37^{\circ} \mathrm{C}$ for $2 \mathrm{~h}$. Antimicrobial activity was presented as percent of killing compared to non-AvBD treated control. Antimicrobial activity of analogues AvBD-12A4 to A6 against E. coli (a), P. aeruginosa (b), S. Typhimurium (c) and S. aureus (d). Wild-type AvBD-6 and AvBD-12 were included as controls. Data are means \pm SD $(n=3)$. Statistical analysis was performed using the one-way analysis of variance (ANOVA) followed by Duncan's test for multiple comparisons using software SPSS version 19.0 (IBM Corp., Armonk, NY). Asterisks indicate statistically significant difference between analogues and AvBD-12 at the same concentrations ( ${ }^{*} p<0.05$ ). Solid line: average killing percent of $32 \mu \mathrm{g} / \mathrm{ml}$ of wild-type AvBD-12. Dash line: average killing percent of $4 \mu \mathrm{g} / \mathrm{ml}$ of wild-type AvBD-12
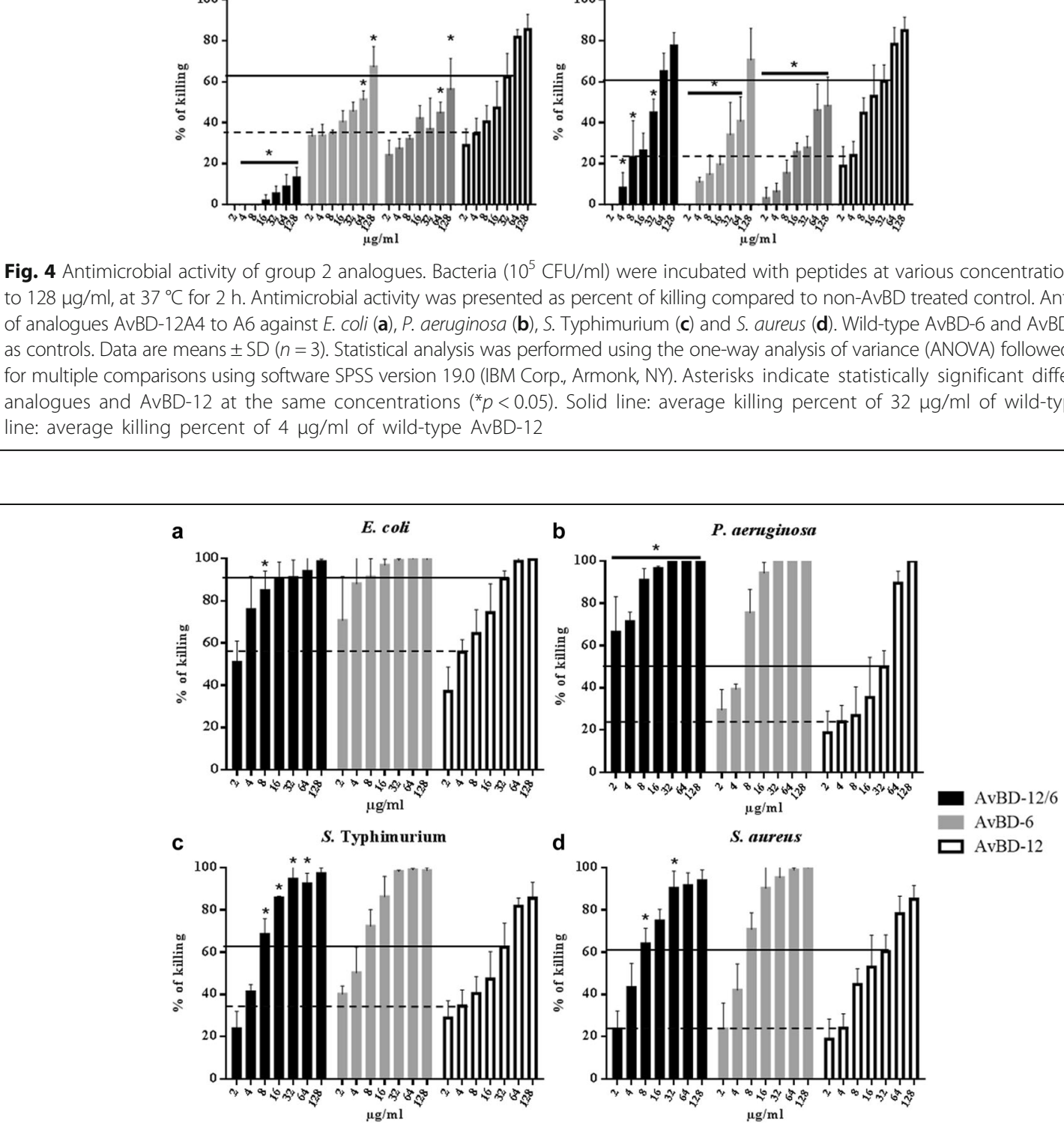

AvBD-12

Fig. 5 Antimicrobial activity of hybrid peptide AvBD-12/6. Bacteria (10 $\mathrm{CFU} / \mathrm{ml})$ were incubated with peptides at various concentrations, ranging from 2 to $128 \mathrm{\mu g} / \mathrm{ml}$, at $37^{\circ} \mathrm{C}$ for $2 \mathrm{~h}$. Antimicrobial activity was presented as percent of killing compared to non-AvBD treated control. Antimicrobial activity of analogue AvBD-12/6 against E. coli (a), P. aeruginosa (b), S. Typhimurium (c) and S. aureus (d). Wild-type AvBD-6 and AvBD-12 were included as controls. Data are means \pm SD $(n=3)$. Statistical analysis was performed using the one-way analysis of variance (ANOVA) followed by Duncan's test for multiple comparisons using software SPSS version 19.0 (IBM Corp., Armonk, NY). Asterisks indicate statistically significant difference between the hybrid analogue and AvBD-12 at the same concentrations ( ${ }^{*} p<0.05$ ). Solid line: average killing percent of $32 \mu \mathrm{g} / \mathrm{ml}$ of wild-type AvBD-12. Dash line: average killing percent of $4 \mu \mathrm{g} / \mathrm{ml}$ of wild-type AvBD-12 
Next, the MICs of AvBD-12A3, the most potent analogue, and the parent AvBD- 6 and AvBD- 12 were evaluated under conditions outlined in CLSI guidelines [27, 28]. High MICs (128 to $256 \mu \mathrm{g} / \mathrm{ml}$ or above) were obtained (Table 2 ).

\section{Susceptibility to $\mathrm{NaCl}$}

The impact of $\mathrm{NaCl}$ on the killing activity of AvBDs was assessed at $\mathrm{NaCl}$ concentrations ranging from 5 to $150 \mathrm{mM}$. Increasing $\mathrm{NaCl}$ concentration had less adverse impact on the killing activity of AvBD-12A2 and AvBD$12 \mathrm{~A} 3$ which had a higher net positive charge $(+9)$ and hydrophobicity (40\%) than AvBD-12 (Fig. 6). AvBD$12 \mathrm{~A} 1$, the most hydrophobic $(53 \%)$ analogue, showed similar or increased susceptibility to $\mathrm{NaCl}$, compared to AvBD-12 (Fig. 6). Susceptibility to $\mathrm{NaCl}$ was also influenced by the bacterial species under investigation. At $150 \mathrm{mM} \mathrm{NaCl}, \mathrm{AvBD}-12 \mathrm{~A} 2$ and AvBD-12A3 retained approximately $80 \%$ of killing potency against $E$. coli and $P$. aeruginosa, but only $30 \%$ to $60 \%$ of killing activity against $S$. Typhimurium and S. aureus (Fig. 6). AvBD12A4, AvBD-12A5, and AvBD-12A6 with fewer disulfide bridges were equally or more susceptible to $\mathrm{NaCl}$ than AvBD-12 (Fig. 7). AvBD-12/6 with the backbone of AvBD-12 and increased net positive charge $(+5)$ resembled AvBD-6 instead of AvBD-12 (Fig. 8).

\section{Cytotoxicity to host cells}

Cell cytotoxicity of most potent analogue AvBD-12A3 $(+9)$ and the hybrid analogue AvBD-12/6 (+5) was determined. Exposure of chicken macrophage cell lines HD11 and MQ-NCSU, murine dendritic cell line JAWSII and CHO-K1 cells to AvBDs at concentrations of 4, 16, 64, $256 \mu \mathrm{g} / \mathrm{ml}$ for $4,12,24$, and $48 \mathrm{~h}$ did not affect cell variability. Data on the highest peptide concentration $(256 \mu \mathrm{g} /$ $\mathrm{ml}$ ) at various exposure times were presented in Additional file 1: Figure S1. The results were consistent with our previous findings that AvBD- 6 and AvBD-12 were non-cytotoxic to avian and mammalian cell lines [26].

\section{Chemotactic activity}

Group 1 analogues AvBD-12A1, AvBD-12A2 and AvBS-12A3 showed minimal chemotactic activity for CCR2-CHO cells (Fig. 9a). However, AvBD-12A2 and AvBD-12A3 at $64 \mu \mathrm{g} / \mathrm{ml}$ demonstrated mild (C.I. $=2.37$; $35.9 \%$ of wild type) and modest (C.I. $=3.74 ; 56.6 \%$ of wild type) chemotactic activity, respectively, for JAWSII cells (Fig. 9b). Analogues AvBD-12A4 with two disulfide bridges had mild chemotactic activity for CCR2$\mathrm{CHO}$ (C.I. $=1.48$ to 2.18 ) and JAWSII cells (C.I. = 1.05 to 1.86$)$ which were significantly below the chemotactic index of parent peptide AvBD-12 $(p<$ 0.01, Fig. 9c and d). AvBD-12A5 with one disulfide bridge and AvBD-12A6 with zero disulfide bridges lost their chemotactic activity for both CCR2-CHO$\mathrm{K} 1$ and JAWSII cells (Fig. 9c and d). The hybrid AvBD-12/6 retained the chemotactic function of the backbone peptide AvBD-12 (Fig. 9e and f).

\section{SEM observation}

Mid-logarithmic-phase $S$. Typhimurium bacteria treated with AvBD-12A3 (Fig. 10a), AvBD-12/6 (Fig. 10b), AvBD-12 (Fig. 10c) and AvBD-6 (Fig. 10d) displayed cell membrane damage (arrow 1) and cell deformation (arrow 2). Mid-logarithmic-phase S. Typhimurium cells treated with PBS showed normal size and intact structure (Fig. 10f, arrow 4). Cell death in stationary-phase culture (Fig. 10e, arrow 3) showed loss of intracellular content and uniform membrane structure.

\section{Discussion}

Due to the broad spectrum antimicrobial activity, LPSneutralizing property, immunomodulatory function and the low cell cytotoxicity, defensins may serve as natural antimicrobial peptides or templates for novel drug design $[14,20,26,34,35]$. It has been reported that the three conserved disulfide bridges are required for the chemotactic function, but not the antimicrobial activity

Table 2 The minimum inhibitory concentration and minimum bactericidal concentration of AvBD analogues

\begin{tabular}{|c|c|c|c|c|c|c|c|c|c|c|c|c|}
\hline \multirow{2}{*}{$\begin{array}{l}\text { Bacteria } \\
\text { (strain) } \\
\text { Defensins }\end{array}$} & \multicolumn{3}{|c|}{$\begin{array}{l}\text { E. coli } \\
\text { (ATCC 25922) }\end{array}$} & \multicolumn{3}{|c|}{$\begin{array}{l}\text { S. Typhimurium } \\
\text { (ATCC 14028) }\end{array}$} & \multicolumn{3}{|c|}{$\begin{array}{l}\text { P. aeruginosa } \\
\text { (ATCC 27853) }\end{array}$} & \multicolumn{3}{|c|}{$\begin{array}{l}\text { S. aureus } \\
\text { (ATCC 29213) }\end{array}$} \\
\hline & MIC-IS & MBC-Is & $\mathrm{MIC}$ & MIC-Is & MBC-Is & $\mathrm{MIC}$ & MIC-IS & MBC-Is & MIC & MIC-Is & MBC-Is & MIC \\
\hline $\mathrm{AvBD}-12-\mathrm{A} 1$ & 8 & 32 & N/A & 32 & 128 & N/A & 32 & 256 & N/A & 256 & $>256$ & N/A \\
\hline$A v B D-12-A 2$ & 4 & 16 & N/A & 16 & 64 & N/A & 16 & 32 & N/A & 256 & 256 & N/A \\
\hline$A v B D-12-A 3$ & 4 & 16 & 128 & 16 & 64 & $>256$ & 8 & 16 & $>256$ & 128 & 256 & $>256$ \\
\hline $\mathrm{AvBD}-12-\mathrm{A} 4$ & 128 & $>256$ & N/A & 256 & $>256$ & N/A & 256 & $>256$ & N/A & $>256$ & $>256$ & N/A \\
\hline AvBD-12-A5 & 64 & 256 & N/A & 256 & $>256$ & N/A & 256 & $>256$ & N/A & $>256$ & $>256$ & N/A \\
\hline$A v B D-12-A 6$ & 64 & 256 & N/A & 256 & $>256$ & $\mathrm{~N} / \mathrm{A}$ & 256 & $>256$ & N/A & $>256$ & $>256$ & N/A \\
\hline$A v B D-12 / 6$ & 8 & 32 & 256 & 16 & 64 & $>256$ & 64 & 256 & $>256$ & 256 & 256 & 256 \\
\hline AvBD-6 & 4 & 16 & 128 & 16 & 64 & $>256$ & 64 & 128 & $>256$ & 256 & 256 & 256 \\
\hline AvBD-12 & 32 & 128 & 256 & 128 & 256 & $>256$ & 128 & $>256$ & $>256$ & 256 & 256 & $>256$ \\
\hline
\end{tabular}


a

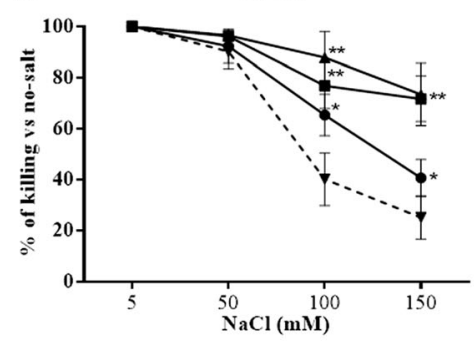

C

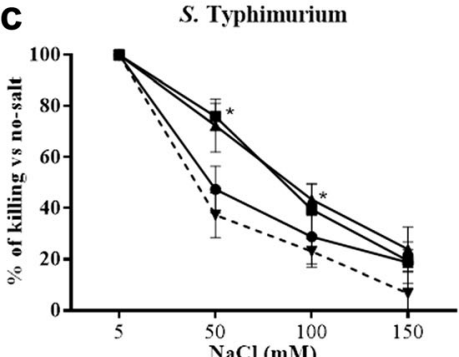

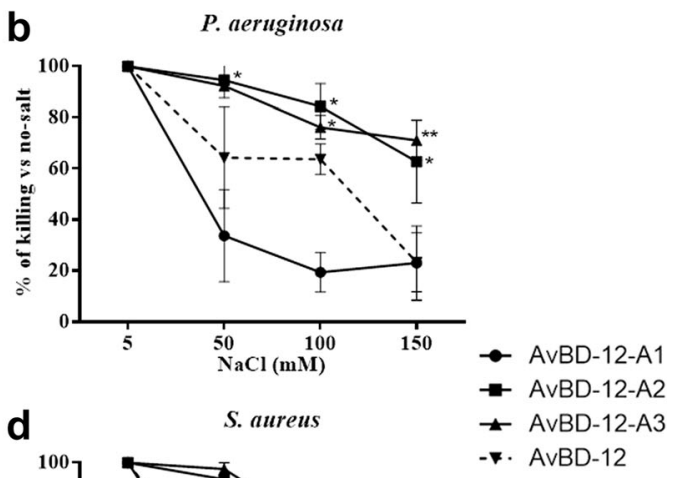

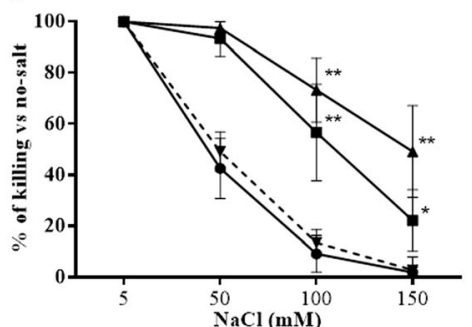

Fig. 6 Effect of $\mathrm{NaCl}$ on the antimicrobial activity of group one AvBDs. Bacteria were treated with group one analogues in the presence of $5 \mathrm{mM}$, $50 \mathrm{mM}, 100 \mathrm{mM}$ or $150 \mathrm{mM} \mathrm{NaCl}$. AvBDs were used at the following concentrations: $16 \mu \mathrm{g} / \mathrm{ml}$ against E. coli (a), $32 \mu \mathrm{g} / \mathrm{ml}$ against $P$. aeruginosa (b) and S. Typhimurium (c) and $64 \mathrm{\mu g} / \mathrm{ml}$ against S. aureus (d). These concentrations were chosen to ensure more than $50 \%$ of killing of inoculum by majority of analogues. Results are expressed as percent of killing compared to the no-salt control. Data shown are means \pm SD $(n=3)$. Statistical analysis was performed using the one-way analysis of variance (ANOVA) followed by Duncan's test for multiple comparisons using software SPSS version 19.0 (IBM Corp., Armonk, NY). Asterisks indicate statistically significant difference among different treatment groups $\left({ }^{*} p<0.05,{ }^{* *} p<0.01\right)$
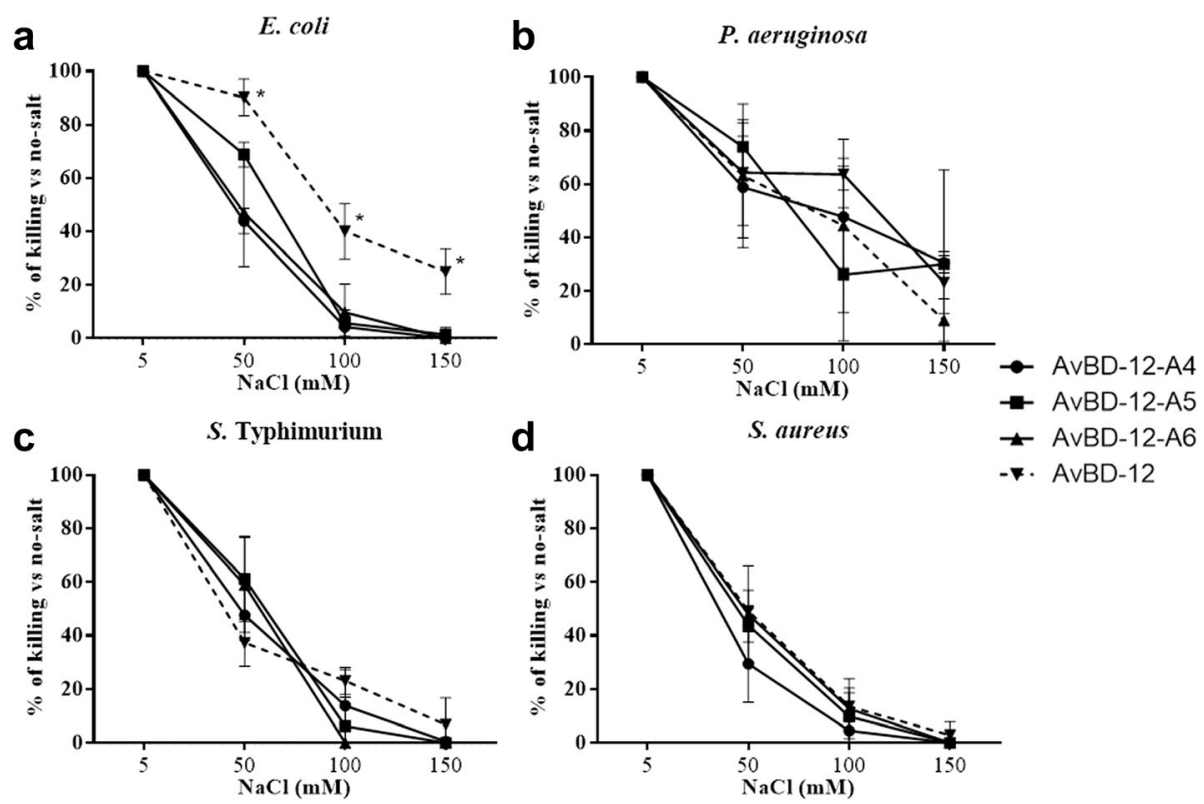

Fig. 7 Effect of $\mathrm{NaCl}$ on the antimicrobial activity of group two analogues. Bacteria were treated with group two analogues in the presence of $5 \mathrm{mM}$, $50 \mathrm{mM}, 100 \mathrm{mM}$ or $150 \mathrm{mM} \mathrm{NaCl}$. AvBDs were used at the following concentrations: $16 \mu \mathrm{g} / \mathrm{ml}$ against $E$. coli (a), $32 \mu \mathrm{g} / \mathrm{ml}$ against $P$. aeruginosa (b) and S. Typhimurium (c) and $64 \mathrm{\mu g} / \mathrm{ml}$ against S. aureus (d). These concentrations were chosen to ensure more than $50 \%$ of killing of inoculum by majority of analogues. Results are expressed as percent of killing compared to the no-salt control. Data shown are means \pm SD $(n=3)$. Statistical analysis was performed using the one-way analysis of variance (ANOVA) followed by Duncan's test for multiple comparisons using software SPSS version 19.0 (IBM Corp., Armonk, NY). Asterisks indicate statistically significant difference among different treatment groups $\left({ }^{*} p<0.05,{ }^{* *} p<0.01\right.$ ) 

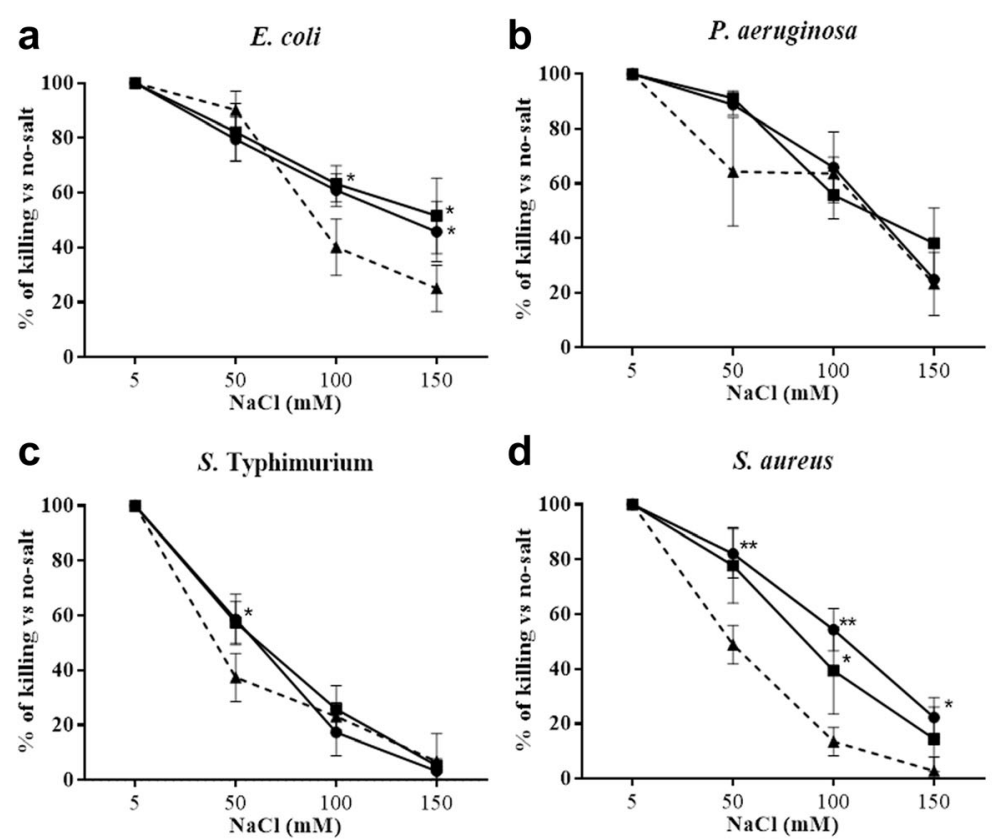

Fig. 8 Effect of $\mathrm{NaCl}$ on the antimicrobial activity activity of group three analogue AvBD-12/6. Bacteria were treated with AvBDs in the presence of $5 \mathrm{mM}, 50 \mathrm{mM}, 100 \mathrm{mM}$ or $150 \mathrm{mM} \mathrm{NaCl}$. AvBDs were used at the following concentrations: $16 \mu \mathrm{g} / \mathrm{ml}$ against E. coli (a), $32 \mu \mathrm{g} / \mathrm{ml}$ against P. aeruginosa (b) and S. Typhimurium (c) and $64 \mu \mathrm{g} / \mathrm{ml}$ against S. aureus (d). These concentrations were chosen to ensure more than $50 \%$ of killing of inoculum by majority of analogues. Results are expressed as percent of killing compared to the no-salt control. Data shown are means \pm SD $(n=3)$. Statistical analysis was performed using the one-way analysis of variance (ANOVA) followed by Duncan's test for multiple comparisons using software SPSS version 19.0 (IBM Corp., Armonk, NY). Asterisks indicate statistically significant difference among different treatment groups ( ${ }^{*} p<0.05$, ** $\left.p<0.01\right)$

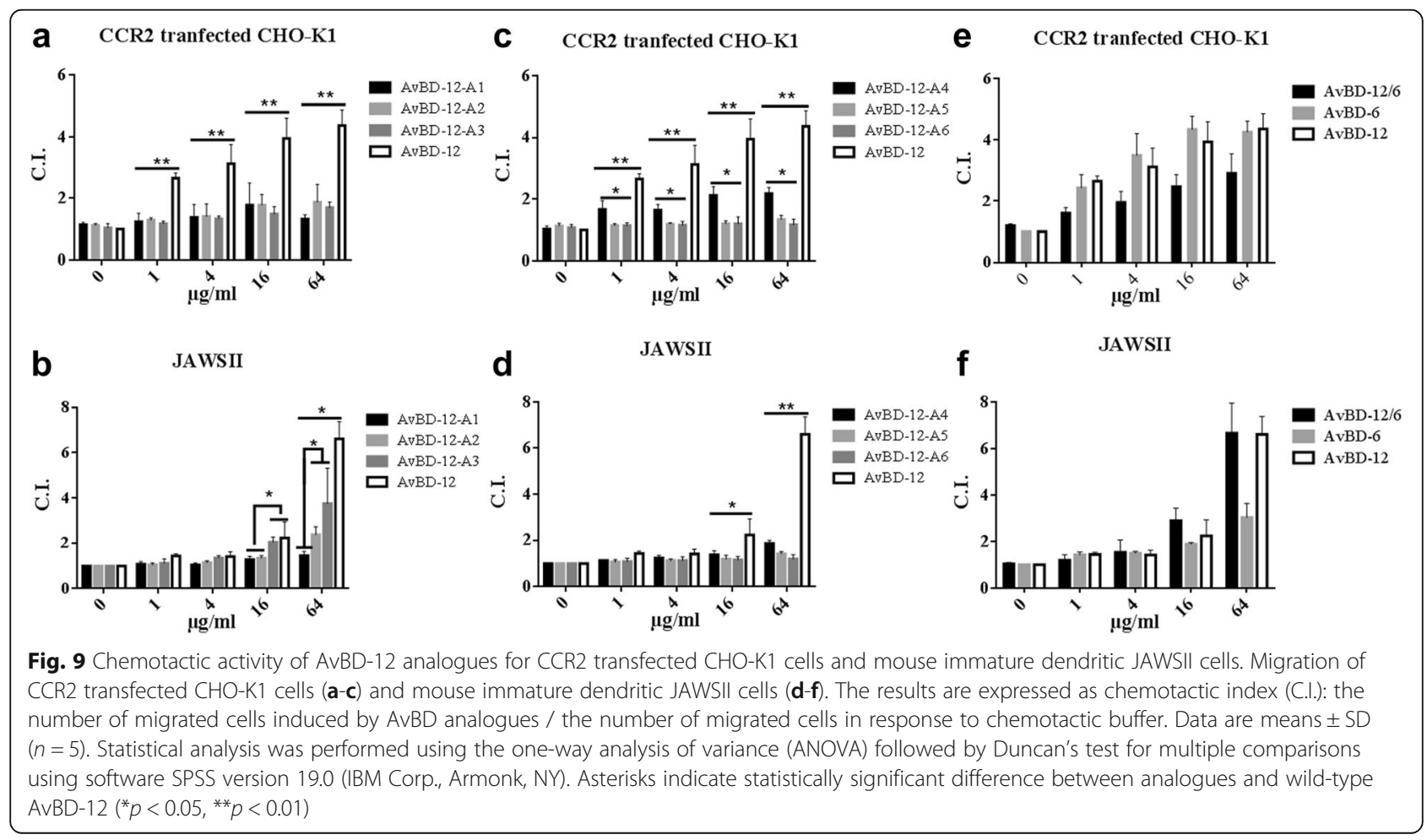



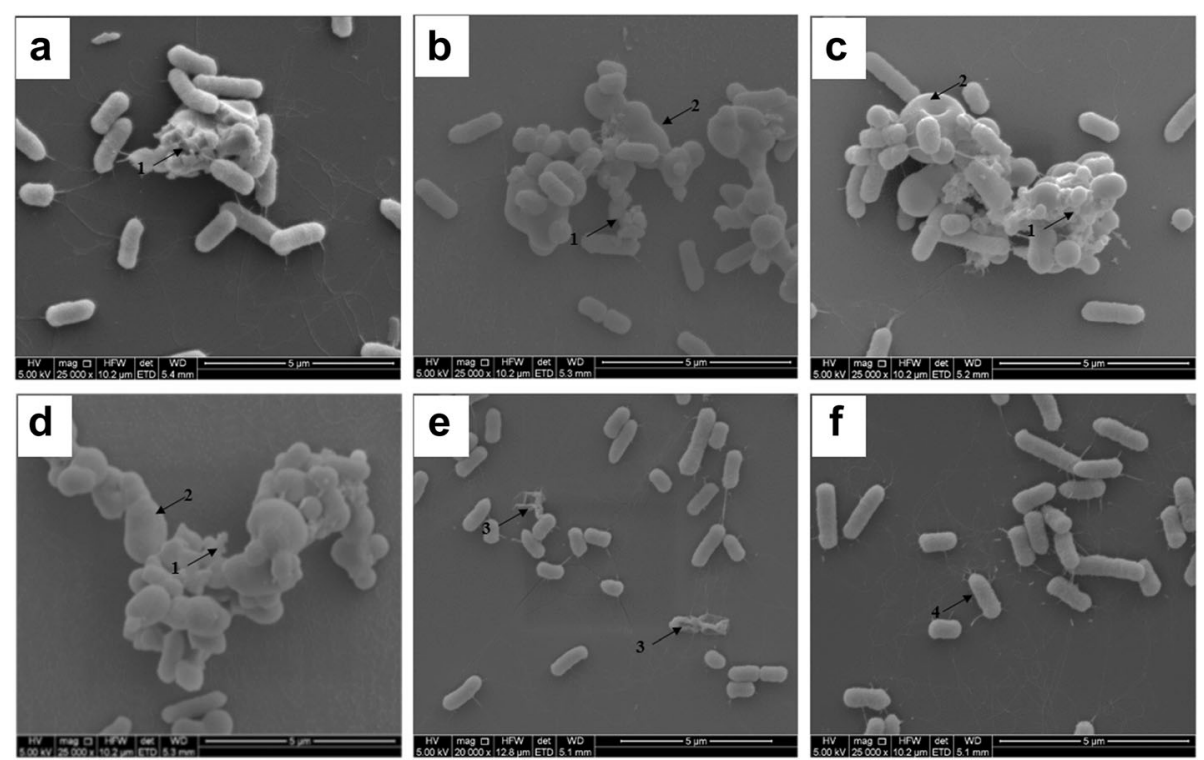

Fig. 10 Scanning electron microscopy (SEM) of S. Typhimurium treated with AvBDs. Mid-logarithmic-phase S. Typhimurium cells ( $10^{8} \mathrm{CFU}$ ) were incubated with AvBDs at a final concentration of $1 \times$ MIC-Is for 30 min. a AvBD-12A3, b AvBD-12/6, c AvBD-12, d AvBD-6, e Stationary phase bacteria, f Mid-logarithmic-phase S. Typhimurium treated with PBS. Arrow 1, membrane damage. Arrow 2, cell deformation. Arrow 3, cell death in stationary-phase culture. Arrow 4, a normal cell in mid-logarithmic-phase culture. Scale bar: $5 \mu \mathrm{m}$

of mammalian $\beta$-defensins $[17,22-25]$. However, data from our previous studies indicate that the correct formation of disulfide bridges via oxidative folding is required for maximum antimicrobial activity [21, 26]. In an effort to identify key structural components important to the antimicrobial and chemotactic activities of AvBDs, we compared the predicted three dimensional structures of AvBDs with the well characterized structure of human beta-defensin 6 (hBD6). It was previously shown that the N-terminal $\alpha$-helix and an adjacent $\beta 2$ $\beta 3$ loop form a contiguous binding surface for CCR2 [32]. The presence of a similar CCR2 binding domain in AvBD-12 may account for the chemotactic activity of AvBD-12 for both avian and mammalian immune cells because AvBD-6 which had an N-terminal coil instead of the $\alpha$-helix was chemotactic only for avian cells [26].

To further understand the structure-activity relationship, we designed and evaluated seven synthetic analogues of AvBD-12. In the first group of analogues, disulfide bridges were removed by replacing cysteines with structurally similar residues (alanine or serine) whereas peptide hydrophobicity and charge were increased by substituting negatively charged residues with hydrophobic (AvBD-12A1) or positively charged residues (AvBD-12A2 and A3). All members of the first group demonstrated stronger antimicrobial activity than their parent peptide AvBD-12, indicating that cysteine-free (linear) AvBDs with a high net positive charge and moderate hydrophobicity can be potent antimicrobial agents. Such linear peptides can be synthesized without oxidative folding which simplifies the production process and reduces cost. In the present study, anti-S. Typhimurium activity of AvBD-12A1 decreased significantly as peptide concentration increased from $64 \mu \mathrm{g} / \mathrm{ml}$ to $128 \mu \mathrm{g} / \mathrm{ml}$ (Fig. 3c). Similar results were obtained repeatedly, suggesting that the decrease was unlikely caused by technical errors. We hypothesize that AvBD-12A1, the most hydrophobic $(53 \%)$ peptide may form aggregates which interferes with peptide binding to Salmonella membrane components, resulting in a reduction in antimicrobial potency. Interestingly, AvBD-12A2 and AvBD-12A3 with identical charge and hydrophobicity, but different locations of three alanine and three serine residues (AvBD-12A3: S5S12S17A27A34A35 and AvBD-12A3: A5A12A17S27S34S35) showed significant difference in antimicrobial and chemotactic activities. Structural analysis of AvBD-12A3 revealed an outward protrusion of R29 side chain and parallel twist F28 aromatic ring. We hypothesize that the outward protrusion of a positively charged residue and an adjacent aromatic ring enhances the interaction between AvBD-12A3 and microbial surface components or CCR2, thereby facilitating antimicrobial and chemotactic functions.

To assess the role of disulfide bridges independent of charge and hydrophobicity, we replaced cysteine residues with isosteric $\alpha$-aminobutyric acids ( $\mathrm{Abu}, \mathrm{U}$ ) to create group 2 analogues. Our data indicated that missing even one conserved disulfide bridge resulted in a significant reduction in AvBD's chemotactic activity. Elimination of two or three disulfide bridges completely abolished the 
chemotactic activity for both avian CCR2-positive cells and murine immature dendritic cells. It has been shown that $C^{1}$ and $C^{4}$ essential to the formation of first and second disulfide bridges are located at the CCR2 binding center [32]. Thus substitution of $C$ with $U$ may have disrupted the CCR2 binding surface, resulting in the loss of chemotactic activity. Our data also showed that removal of disulfide bridges had varying degrees of negative impact on AvBD's antimicrobial activity. Analogue AvBD12A4 missing the $C^{1}-C^{5}$ bridge was nearly inactive against $S$. Typhimurium. These results collectively suggest that all three disulfide bridges are needed in the natural form of AvBDs to maintain tertiary structural features critical to interacting with microbial surface components and CCRs on immune cells.

Besides antimicrobial assays, SEM was performed to illustrate the killing mechanisms of AvBD-12 analogues. Treatment of $S$. Typhimurium with AvBD-12A3 and AvBD-12/6, and wild-type AvBD-6 and AvBD-12 caused similar ultrastructural changes, including cell deformation and membrane damage. Giant cells were only observed among treatment groups, indicating membrane permeabilization is an essential step in the killing of microbes by AvBDs.

Salt sensitivity is a major obstacle to the application of $\beta$-defensins as chemotherapeutic agents. Different strategies have been explored to increase the resistance of beta-defensins to salts, such as $\mathrm{N}$-terminal deletion [36], combining sequences of HBD-1 and salt-resistant $\theta$-defensin [37] and replacement of tryptophan or histidine with a bulky amino acid $\beta$-naphthylalanine [38]. In the present study, we found that increasing peptide charge significantly reduced the impact of $\mathrm{NaCl}$ on the antimicrobial efficacy of AvBD-12A2 and AvBD-12A3. However, the activity against $\mathrm{S}$. Typhimurium was still severely inhibited by physiological concentration of $\mathrm{NaCl}$ $(150 \mathrm{mM})$, suggesting that different mechanisms are involved in killing different bacterial species.

In the present study, we also determined the minimum inhibitory concentrations (MICs) of AvBDs. Using the standard Muller Hinton II broth, the MICs of the parent AvBDs and the most potent analogue AvBD-12A3 were much higher than the MIC values obtained under the low-salt and low-nutrient condition. We hypothesize that interference of initial peptide-bacteria interactions by cationic salts as well as enzymatic degradation or modification of AvBDs during bacterial growth in a nutrient rich Mueller-Hinton broth might have contributed to the decreased antimicrobial activity. It has been shown that human cathelicidin LL-37 could be hydrolyzed by $S$. aureus protease or cleaved by metalloprotease, gelatinase or cysteine protease produced by other bacterial species [39]. Proteolytic degradation is one of the main mechanisms that both gram-positive and gram-negative bacteria use to evade host antimicrobial peptide killing [40-45]. Further modification is clearly needed to improve the efficacy of AvBD-12A3 as an antimicrobial agent. It is noteworthy that all AvBD analogues remain non-cytotoxic to avian and mammalian cells.

\section{Conclusions}

The three conserved disulfide bridges maintaining the tertiary structure of natural AvBDs are required not only for the chemotactic activity, but also for maximum antimicrobial activity. AvBD-12A3 with increased net positive charge and a CCR2-binding domains (N-terminal $\alpha$ helix and $\beta 2-\beta 3$ loop) demonstrated potent antimicrobial activity and retained partial chemotactic property. Analogue AvBD-12A3 may serve as a template for the design of novel antimicrobial peptides as therapeutic agents for both avian and mammalian hosts.

\section{Additional file}

Additional file 1: Figure S1. Cytotoxicity of analogues $A v B D-12 A 3$ and AvBD-12/6. Effect of $256 \mu \mathrm{g} / \mathrm{ml}$ of AvBD-12A3, AvBD-12/6, AvBD-6 and AvBD-12 on the metabolic activity of MQ-NCSU, HD11, JAWSII and CHO-K1 cells after 4, 12, 24 and 48 hours of incubation. The results are expressed as the percentage of viability relative to the untreated control. The data are means \pm SD $(n=3)$. Student $t$-test was performed to analyze differences between AvBD-treated and untreated cells. No significant difference was found. (TIFF $391 \mathrm{~kb}$ )

\section{Abbreviations}

(MBC): Minimum bactericidal concentration; ANOVA: One-way analysis of variance; AvBD: Avian beta-defensin; BSA: Bovine serum albumin;

C.I.: Chemotaxis index; CFU: Colony-forming unit; DCs: Dendritic cells; ESIMS: Electrospray ionization mass spectrometry; FBS: Fetal bovine serum; fMLF: N-Formyl-methionyl-leucyl-phenylalanine; Fmoc: 9-fluorenyl-methoxycarbonyl; GFP: Green fluorescent protein; GM-CSF: Granulocyte macrophage colony-stimulating factor; hBD6: Human $\beta$-defensin 6, LB: Luria-Bertani; LPS: Lipopolysaccharides; LTA: Lipoteichoic acid; MIC: Minimum inhibitory concentration; PBS: Phosphate buffered saline; RP-HPLC: Reversed-phase high performance liquid chromatography; SD: Standard deviation;

SEM: Scanning electron microscopy; TSA: Trypticase soy agar

\section{Acknowledgements}

We would like to thank the Electron Microscopy Core Facility at the University of Missouri for assistance with SEM work. We thank Dr. Thomas Reilly for many meaningful discussions concerning peptide structure and function. We thank Christine Zhang for editing the manuscript.

\section{Funding}

The present study was partially funded by the University of Missouri College of Veterinary Medicine.

\section{Availability of data and materials}

The datasets supporting the conclusions of this article are included within the article.

\section{Authors' contributions}

Conceived and designed the experiments: MY, MZ, SZ. Performed the experiments: MY, CZ. Analyzed the data: MY, CZ, TR, SZ. Contributed reagents/materials/analysis tools: MZ, SZ. Drafted the manuscript: MY, CZ, SZ. All authors read and approved the manuscript 


\section{Competing interests}

The authors declare that they have no competing interests.

\section{Consent for publication}

Not applicable.

\section{Ethics approval and consent to participate}

Not applicable.

\section{Author details}

'Department of Veterinary Pathobiology, College of Veterinary Medicine, University of Missouri, Columbia, MO 65211, USA. ${ }^{2}$ Department of Biomedical Science, College of Veterinary Medicine, University of Missouri, Columbia, MO 65211, USA. ${ }^{3}$ Veterinary Medical Diagnostic Laboratory, College of Veterinary Medicine, University of Missouri, Columbia, MO 65211, USA.

Received: 14 November 2016 Accepted: 14 February 2017 Published online: 23 February 2017

\section{References}

1. Donoghue DJ. Antibiotic residues in poultry tissues and eggs: human health concerns? Poult Sci. 2003;82(4):618-21.

2. Ventola CL. The antibiotic resistance crisis: part 1: causes and threats. Pharmacy and Ther. 2015;40(4):277-83.

3. Catry B, Laevens H, Devriese LA, Opsomer G, De Kruif A. Antimicrobial resistance in livestock. J Vet Pharmacol Ther. 2003:26(2):81-93.

4. Soulsby EJ. Resistance to antimicrobials in humans and animals. BMJ (Clinical research ed). 2005;331(7527):1219-20.

5. Ventola CL. The antibiotic resistance crisis: part 2: management strategies and new agents. Pharmacy and Ther. 2015;40(5):344-52.

6. Bulet $P$, Stocklin R, Menin L. Anti-microbial peptides: from invertebrates to vertebrates. Immunol Rev. 2004;198:169-84.

7. Cuperus T, Coorens M, van Dijk A, Haagsman HP. Avian host defense peptides. Dev Comp Immunol. 2013;41(3):352-69.

8. Ganz T. Defensins: antimicrobial peptides of innate immunity. Nat Rev Immunol. 2003;3(9):710-20.

9. Lehrer RI. Primate defensins. Nat Rev Microbiol. 2004:2(9):727-38.

10. van Dijk A, Veldhuizen EJ, Haagsman HP. Avian defensins. Vet Immunol Immunopathol. 2008;124(1-2):1-18.

11. Lai Y, Gallo RL. AMPed up immunity: how antimicrobial peptides have multiple roles in immune defense. Trends Immunol. 2009:30(3):131-41.

12. Semple F, MacPherson H, Webb S, Cox SL, Mallin LJ, Tyrrell C, Grimes GR, Semple CA, Nix MA, Millhauser GL, et al. Human beta-defensin 3 affects the activity of pro-inflammatory pathways associated with MyD88 and TRIF. Eur J Immunol. 2011;41(11):3291-300.

13. Verma C, Seebah S, Low SM, Zhou L, Liu SP, Li J, Beuerman RW. Defensins: antimicrobial peptides for therapeutic development. Biotechnol J. 2007; 2(11):1353-9.

14. Zhang G, Sunkara LT. Avian antimicrobial host defense peptides: from biology to therapeutic applications. Pharmaceuticals (Basel). 2014;7(3):220-47.

15. Yeaman MR, Yount NY. Mechanisms of antimicrobial peptide action and resistance. Pharmacol Rev. 2003;55(1):27-55.

16. Rohrl J, Yang D, Oppenheim JJ, Hehlgans T. Human beta-defensin 2 and 3 and their mouse orthologs induce chemotaxis through interaction with CCR2. J Immunol. 2010;184(12):6688-94.

17. Wu Z, Hoover DM, Yang D, Boulegue C, Santamaria F, Oppenheim JJ, Lubkowski J, Lu W. Engineering disulfide bridges to dissect antimicrobial and chemotactic activities of human beta-defensin 3. Proc Natl Acad Sci U S A. 2003;100(15):8880-5.

18. Yang D, Chertov O, Bykovskaia SN, Chen Q, Buffo MJ, Shogan J, Anderson M, Schroder JM, Wang JM, Howard OM, et al. Beta-defensins: linking innate and adaptive immunity through dendritic and T cell CCR6. Science. 1999; 286(5439):525-8.

19. Aoki W, Ueda M. Characterization of antimicrobial peptides toward the development of novel antibiotics. Pharmaceuticals (Basel). 2013;6(8):1055-81.

20. Ma D, Lin L, Zhang K, Han Z, Shao Y, Liu X, Liu S. Three novel Anas platyrhynchos avian beta-defensins, upregulated by duck hepatitis virus, with antibacterial and antiviral activities. Mol Immunol. 2011:49(1-2):84-96.

21. Zhao $L$, Yang $M$, Zhang $M$, Zhang $S$. Expression, purification, and in vitro comparative characterization of avian beta-defensin-2, -6 , and -12 . Avian Dis. 2014;58(4):541-9.
22. Hoover DM, Wu Z, Tucker K, Lu W, Lubkowski J. Antimicrobial characterization of human beta-defensin 3 derivatives. Antimicrob Agents Chemother. 2003; 47(9):2804-9.

23. Krishnakumari V, Sharadadevi A, Singh S, Nagaraj R. Single disulfide and linear analogues corresponding to the carboxy-terminal segment of bovine beta-defensin-2: effects of introducing the beta-hairpin nucleating sequence d-pro-gly on antibacterial activity and Biophysical properties. Biochemistry. 2003:42(31):9307-15.

24. Kluver E, Schulz-Maronde S, Scheid S, Meyer B, Forssmann WG, Adermann K. Structure-activity relation of human beta-defensin 3: influence of disulfide bonds and cysteine substitution on antimicrobial activity and cytotoxicity. Biochemistry. 2005;44(28):9804-16.

25. Mandal M, Jagannadham MV, Nagaraj R. Antibacterial activities and conformations of bovine beta-defensin BNBD-12 and analogs:structural and disulfide bridge requirements for activity. Peptides. 2002;23(3):413-8.

26. Yang M, Zhang C, Zhang X, Zhang MZ, Rottinghaus GE, Zhang S. Structurefunction analysis of Avian beta-defensin-6 and beta-defensin-12: role of charge and disulfide bridges. BMC Microbiol. 2016;16(1):210.

27. Clinical and Laboratory Standards Institute. M07-A8: Methods for dilution antimicrobial susceptibility tests for bacteria that grow aerobically, approved standard. 8th ed. Wayne: CLSI; 2009.

28. Clinical and Laboratory Standards Institute. M100-S22: Performance standards for antimicrobial susceptibility testing, 22nd informational suppl. Wayne: CLSI; 2012

29. French GL. Bactericidal agents in the treatment of MRSA infections-the potential role of daptomycin. J Antimicrob Chemother. 2006;58(6):1107-17.

30. Falk W, Goodwin Jr RH, Leonard EJ. A 48-well micro chemotaxis assembly for rapid and accurate measurement of leukocyte migration. J Immunol Methods. 1980;33(3):239-47.

31. Cobo ER, Kissoon-Singh V, Moreau F, Chadee K. Colonic MUC2 mucin regulates the expression and antimicrobial activity of beta-defensin 2. Mucosal Immunol. 2015:8(6):1360-72.

32. De Paula VS, Gomes NS, Lima LG, Miyamoto CA, Monteiro RQ, Almeida FC, Valente AP. Structural basis for the interaction of human beta-defensin 6 and its putative chemokine receptor CCR2 and breast cancer microvesicles. Mol Biol. 2013:425(22):4479-95

33. Dragelj JL, Stanković IM, Božinovski DM, Meyer T, Veljković DŽ, Medaković VB, Knapp E-W, Zarić SD. C-H/O interactions of aromatic CH donors within proteins: a crystallographic study. Cryst Growth Des. 2016;16(4):1948-57.

34. Soman SS, Nair S, Issac A, Arathy DS, Niyas KP, Anoop M, Sreekumar E. Immunomodulation by duck defensin, Apl_AvBD2: in vitro dendritic cell immunoreceptor (DCIR) mRNA suppression, and B- and T-lymphocyte chemotaxis. Mol Immunol. 2009;46(15):3070-5.

35. Yacoub HA, Elazzazy AM, Abuzinadah OA, Al-Hejin AM, Mahmoud MM, Harakeh SM. Antimicrobial activities of chicken beta-defensin (4 and 10) peptides against pathogenic bacteria and fungi. Front Cell Infect Microbiol. 2015:5:36.

36. Li T, Guo F, Wang Q, Fang H, Li Z, Wang D, Wang H. N-terminus three residues deletion mutant of human beta-defensin 3 with remarkably enhanced salt-resistance. PLoS One. 2015;10(2):e0117913.

37. Olli S, Nagaraj R, Motukupally SR. A hybrid cationic peptide composed of human beta-defensin-1 and humanized theta-defensin sequences exhibits salt-resistant antimicrobial activity. Antimicrob Agents Chemother. 2015; 59(1):217-25.

38. Chu HL, Yu HY, Yip BS, Chih YH, Liang CW, Cheng HT, Cheng JW. Boosting salt resistance of short antimicrobial peptides. Antimicrob Agents Chemother. 2013;57(8):4050-2.

39. Shinnar AE, Butler KL, Park HJ. Cathelicidin family of antimicrobial peptides: proteolytic processing and protease resistance. Bioorg Chem. 2003;31(6): 425-36.

40. Jin T, Bokarewa M, Foster T, Mitchell J, Higgins J, Tarkowski A. Staphylococcus aureus resists human defensins by production of staphylokinase, a novel bacterial evasion mechanism. J Immunol. 2004; 172(2):1169-76

41. Ernst CM, Staubitz P, Mishra NN, Yang SJ, Hornig G, Kalbacher H, Bayer AS, Kraus D, Peschel A. The bacterial defensin resistance protein MprF consists of separable domains for lipid lysinylation and antimicrobial peptide repulsion. PLoS Pathog. 2009:5(11):e1000660.

42. Nawrocki KL, Crispell EK, McBride SM. Antimicrobial peptide resistance mechanisms of gram-positive bacteria. Antibiotics (Basel, Switzerland). 2014;3(4):461-92. 
43. Malanovic N, Lohner K. Gram-positive bacterial cell envelopes: The impact on the activity of antimicrobial peptides. Biochim Biophys Acta. 2016; 1858(5):936-46.

44. Cole JN, Nizet V. Bacterial Evasion of Host Antimicrobial Peptide Defenses. Microbiology spectrum. 2016;4(1):1-37.

45. Joo HS, Fu Cl, Otto M. Bacterial strategies of resistance to antimicrobial peptides. Philosophical transactions of the Royal Society of London Series B, Biological sciences. 2016;371(1695):1-11.

Submit your next manuscript to BioMed Central and we will help you at every step:

- We accept pre-submission inquiries

- Our selector tool helps you to find the most relevant journal

- We provide round the clock customer support

- Convenient online submission

- Thorough peer review

- Inclusion in PubMed and all major indexing services

- Maximum visibility for your research

Submit your manuscript at www.biomedcentral.com/submit 